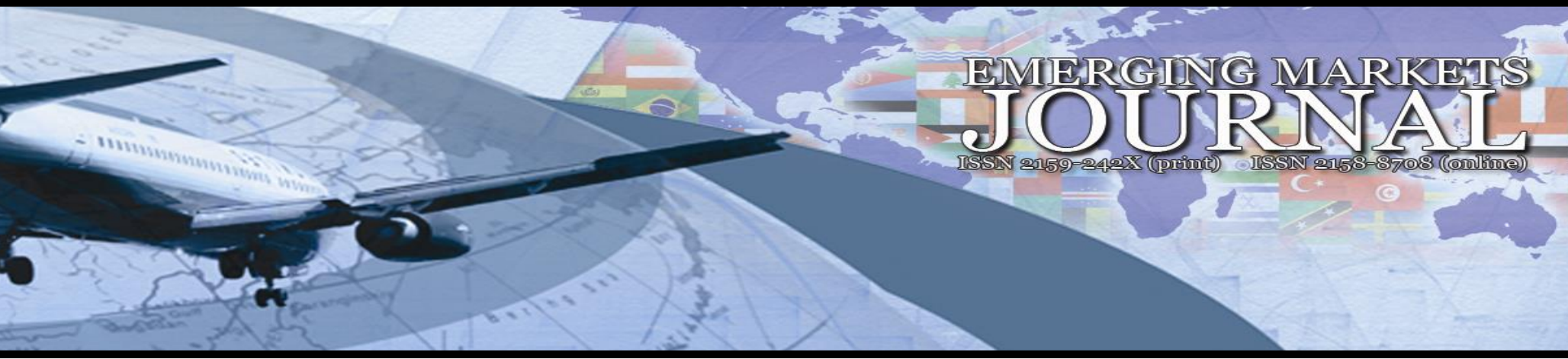

\title{
Business Process Reengineering and the Performance of Insurance Firms in Nigeria
}

Benneth Uchenna Eze

Hallmark University, Nigeria | beneze7@gmail.com

Saidi Adedeji Adelekan

Mountain Top University, Nigeria | saadelekan@mtu.edu.ng

\section{Emmanuel Kanayo Nwaba}

Olabisi Onabanjo University, Nigeria | nwabakanayo@gmail.com

Volume 9 No 1 (2019) ｜ ISSN 2158-8708 (online) ｜ DOI 10.5195/emaj.2019.163 | http://emaj.pitt.edu |

Abstract

This study investigated the effect of business process reengineering on the performance of insurance firms in Nigeria, by employing two components of business process reengineering. Survey research design was adopted, through the administration of structured questionnaires on some selected staff of insurance companies at their head offices in Lagos, Nigeria. The research instrument was validated through content validity index (CVI), while the reliability of the research instrument was tested through test-retest method. The findings revealed that, the two components of business process reengineering adopted for this study have individual positive significant effect on insurance firms' performance and adoption of new process. The F-statistics revealed that the two components of business process reengineering adopted for this study have positive significant combined effect on insurance firms' performance in Nigeria. The adjusted coefficient of determination implied that, change in insurance firms' performance is explained by the combined business process reengineering components. It is therefore concluded that, business process reengineering components are important drivers of insurance firms' performance. It is recommended that, insurance firms should introduce new technology that will aid insurance penetration, especially information communication technology (ICT). The deployment of ICT tends to make it easier for existing and new customers to pick-up insurance policies through their smart phones or personal computers. Furthermore, insurance firms should equally come up with reengineered processes. The process of serving their customers should be enhanced.

Keywords: Business Process Reengineering, Insurance Firms, Performance, New Technology, New Process

\section{$(\mathrm{cc}) \mathrm{EY}$}

New articles in this journal are licensed under a Creative Commons Attribution 3.0 United States License.

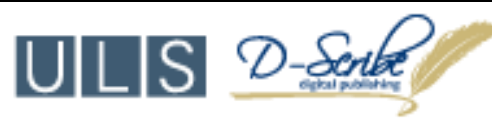

This journal is published by the University Library System of the University of Pittsburgh as part of its D-Scribe Digital Publishing Program, and is cosponsored by the University of Pittsburgh Press. 


\section{Business Process Reengineering and the Performance of Insurance Firms in Nigeria}

\author{
Benneth Uchenna Eze \\ Saidi Adedeji Adelekan \\ Emmanuel Kanayo Nwaba
}

\section{Introduction}

Organizational performance has become a major determinant of firms' corporate existence. As a result, there are unavoidable pressures for organizations to reengineer their business processes for greater effectiveness and efficiency. The goal of business process reengineering is to redesign and change the existing business practices or process to achieve dramatic improvement in organizational performance. In a highly competitive globalized world, organizations enhance competitive advantage through Business Process Reengineering (BPR) by redesigning selected processes. Sharma (2006) posited that, business process reengineering implies transformed processes that together form a component of a larger system aimed at enabling organization to empower themselves with contemporary technologically-based business solutions and innovations.

According to Klun and Trkman (2018), business processes are simply a set of activities that transform a set of inputs into a set of outputs (goods or services) for another person or process using people and equipments. Business process entails a set of logically related tasks performed to achieve a defined business output or outcome. It involves a wide spectrum of activities procurement, order fulfillment, product development, customer service and sales (Okafor \& Okeke-Ezeanyanwu, 2018; Sharma, 2006). Thus, business process reengineering becomes an offshoot of business process. Hammer and Champy (1993) argued that, the fundamental reconsideration and radical redesign of organizational process in order to achieve drastic improvement of current performance in cost, service and speed enjoy a fair measure of consensus.

In Nigeria, the changing dynamics of insurance market has forced players at all levels to reengineer their business process. The insurance operations and functions were redesigned to meet emerging challenges of contemporary insurance activities. Scholars (Okafor \& Okeke-Ezeanyanwu, 2018; Kabiru, Mohamed \& Norlena, 2012; Kemal, Yasin, \& Zafer, 2011) established that, business process reengineering is positively related to firm performance. However, studies examining the effect of business process reengineering on insurance firms' performance are sparse. In addressing this research gap, this study examines the effect of business process reengineering (measured by adoption of new technology and adoption of new process) on insurance firms' performance.
In line with the research objectives, the following hypotheses were formulated:

$\mathrm{H}_{0} 1$. Adoption of new technology does not significantly affect insurance firms' performance.

$\mathrm{H}_{0} 2$ : $\quad$ Adoption of new process does not significantly affect insurance firms' performance.

$\mathrm{H}_{0} 3$ : $\quad$ Business process reengineering components do not have significant effect on insurance firms' performance.

\section{Literature Review}

Business process reengineering (BPR) is a means by which an organization can achieve radical change in performance, by application of a variety of tools and techniques that focus on the business as a set of related customer-related core business processes. According to Jacob (2014), BRP is a solution that is an informed and participative process resulting in new ways of doing business that position a firm for success, both in the short and the long term. Hammer (1990) posits that, BRP is the fundamental rethinking and radical redesign of business processes to achieve dramatic improvement in important contemporary measures of performance such as cost, service quality and speed. Tor and Wendi (1996) are of the opinion that business process reengineering was founded on the premise that significant corporate performance improvement requires continuous improvement, breaking away from the outdated rules and fundamental assumptions that underlie operations. BPR has gained a considerable attention in the world of change management during the past years. Today, more and more organizations are embracing the BPR trend (Okafor \& OkekeEzeanyanwu, 2018; Kabiru, Mohamed \& Norlena, 2012; Klun \& Trkman, 2018). BPR portrays the adoption of new technology and processes in business operations.

Challenges in business environment and competitiveness have called for immediate redesign of business processes to achieve dramatic improvement in cost of business operations, service quality, revenue and profitability. This involves removing outdated processes and using modern information technology to manage business organizations. Hammer and Stanton (2013) opine that, dynamic business environment has called for innovation which is regarded as crucial to the sustainment of competitive advantage. Changing processes and creating new ones is essential for adapting to technological change and competitive pressures. The essence of new technology adoption is to ensure efficiency and effectiveness in operations management within an organization to maximize value and profitability through competitive performance (Okafor \& Okeke-Ezeanyanwu, 2018).

The reengineering process deals with replacing the manual processes with automation and eliminating unnecessary bureaucracy as well as providing right information at the right time to the right people, eliminating unnecessary work, reducing 
unnecessary control, empowering every employee and getting it right the first time. Moreover, automation of key processes can improve the performance of business activities and productivity, increase profitability and enable the enterprise-wide monitoring and coordination. Automated process in certain key areas of production process will lead to reduction in cost of production and achievement of better quality products as well as enhanced revenue (Okafor \& Okeke-Ezeanyanwu, 2018).

Simon (1994) identified value adding as a concept of BPR. The concept of value adding, which was originally developed by Porter (1984) postulates that every firm is a collection of activities that are performed to design, produce, market, deliver and support its product. All these activities can be represented using a value chain. Value chains can be understood in the context of the business unit. In the classical value chain, an organization's activities form a linear flow from the supplier(s) to the customer(s). The value chain includes firstly the "primary activities", that is, the activities the company has to perform in order to justify its right to exist. These activities are adding direct customer value to the product or service and the effective link of these activities has a major impact on the overall performance of the organization. The "secondary activities" are supporting the former, in order to ensure organizational and managerial control, coordination among primary activities, as well as for developing and maintaining a corporate culture within the organization, and a corporate image towards the environment. Their value-adding effect is indirect and can only be realizable through the results of primary activities. Simon (1994) also equally examined the application of BPR on organizational structures, processes and tasks, as well as their location of individuals and changes of work descriptions, positions and titles. The challenge of organizational analysis, design and change has been a concern for almost any theorist within the area of organization in its narrow, as well as wider sense.

Kemal, Yasin, \& Zafer (2011) studied the effects of BPR on productivity and performance by conducting firm level analysis. The objective of the study was to empirically examine the effect of BPR on firm productivity and performance. Data was used spanning between 1987-2008. The findings showed that, return-on-assets drop significantly during the project initiation year. Moreover, it was found out that, performance and productivity measures improve in a decreasing manner after project initiation, suggesting that BPR positively affects firms' performance.

Islam \& Mohamed Bin (2011) conducted a study on the impact of organizational innovation on firm performance drawing evidence from Malaysian-Based ICT firms. The study investigated the effect of organizational innovation on firms' performance. Data for the study were collected through an electronic survey conducted on 115 small and medium enterprises operating in the ICT industry in Malaysia. The findings from the study revealed that, organizational performance has a significant effect on firms' performance.

Kabiru, Mohamed \& Norlena (2012) studied the critical success factors for business process management for small and medium banks in Nigeria, conducting a questionnaire on banks. The finding from the study showed that, there is a significant relationship among information technology investment, personnel commitment, volume financial activities and overall organizational performance. Mura, Nilgun \& Fulya (2013) conducted a study on the relationship between innovation and firm performance by using evidence from Turkish Automotive Supplier Industry. The purpose of the study was to examine the relationship between innovation and firm performance. The authors employed survey research design, through the administration of structured questionnaire on top level managers from 113 firms operating in the automotive supplier industries in Turkey in 2011. The study used regression analysis with the aid of SPSS. The findings from the study revealed that, technological innovation such as product and process innovation have positive and significant impact on firms' performance.

Okafor \& Okeke-Ezeanyanwu (2018) investigated the effect of business process reengineering on organizational performance of rice production firms in South-East Nigeria, using the survey research design. Authors employed multiple regression analysis and found that, the adoption of new technology and processes have positive significant effect on the performance of rice producing firms in South-East, while presence of process owners at production interfaces have negative significant effect. Based on the findings, the study concluded that, if rice production firms in South East Nigeria want to improve performance, attention should be given to the business process reengineering technique.

\section{Methodology}

The survey research design was employed for this study. The exact employees of insurance companies in Nigeria (population of the study) could not be ascertained; as such the exact population of the study could not be determined. However, Kothari and Garg (2014) posit that, if the population of a study is not available, the researcher should employ a population of 20,000. This is because, most sample determination formula designers assign a relatively similar sample size for a population in the range of 20 thousands to 50 million. The study employed Raosoft sample estimation technique at the $95 \%$ confidence level in arriving at a sample size of 377 from the population of 20,000 employees of insurance companies. A $30 \%$ non-response rate was assumed, which gives an aggregate sample size of 490. Purposive sampling method was used to select a sample of 490 staff of some insurance companies (Mutual Benefit Assurance PLC, AIICO Insurance PLC and Standard Alliance Insurance PLC). The study employed a close ended questionnaire to obtain data. Well-structured questionnaire on a seven-point Likert scale ranging from 1 (minimum) to 7 (maximum) was administered on some selected employees of Insurance firms in Nigeria.

The instrument (questionnaire) was validated using content validity index (CVI), through the evaluation of four independent evaluators (two academics and two top executives of insurance firms), that evaluated the instrument on a two-scale (relevant and not relevant). 
The CVI formula: $\mathrm{n} / \mathrm{N}$ was used.

Where;

$\mathrm{n}=$ number of questions rated as relevant

$\mathrm{N}=$ total number of questions

A CVI of 0.786 was obtained, which indicated that the instrument is valid.

The reliability of the instrument was tested using test-retest method. A pilot study was conducted, whereby the instrument was administered twice to twenty employees of Mansard Insurance in Lagos State, Nigeria within an interval of fourteen days. The result of first pilot study was correlated with that of the second, which gave a value of $0.809,0.702$ and 0.749 for adoption of new technology, new process and performance respectively. This implied that, the instrument is consistent. The data were analyzed using multiple regression analysis with the aid of STATA version 14 at the $5 \%$ level of significance.

Model Specification

$\mathrm{PERF}=\mathrm{f}(\mathrm{ANT} \& \mathrm{ANP})$

PERF $=\beta_{0}+\beta_{1}($ ANT $)+\beta_{2}($ ANP $)+\mu_{i}$

Where;

$\mathrm{PERF}=$ Performance

ANT $=$ Adoption of New Technology

$\mathrm{ANP}=$ Adoption of New Process

$\beta_{0}$ is the constant term

$\beta_{1}, \beta_{2}, \beta_{3}$ are the coefficient estimators

$\beta_{1}, \beta_{2}, \beta_{3},>0$

Where $\mu$ is error term

\section{A Priori Expectation}

Based on the study by Okafor and OkekeEzeanyanwu (2018), the two components of business process reengineering (adoption of new technology and new process) are expected to exhibit positive relationship with insurance firms performance. Hence, there will be a direct relationship between adoption of new technology and new process as well as insurance firms' performance.

The research instrument (questionnaire) was administered on 490 staff members of three insurance companies in Lagos, Nigeria (Mutual Benefit Assurance PLC, AIICO Insurance PLC and Standard Alliance Insurance PLC). However, only 381 copies of the questionnaire were returned and found useable, which gave a response rate of $77.7 \%$. Regression analysis was employed in analyzing the data with the aid of STATA version 14.

\section{Findings and Discussion}

This sub-section aggregates the indicators of business process reengineering (adoption of new technology and new process). It estimate the combined effect of these variables on insurance firms' performance as well as ascertaining the individual effect of the variables (through the t-statistics). The model addresses the main objective of the study, which is to examine the effect of business process reengineering on the performance of insurance firms in Nigeria.

Table 1: Result Summary (Dependent Variable Performance)

\begin{tabular}{|l|l|l|l|}
\hline Variable(s) & Coefficient & $\mathrm{t}$ & P-Value \\
\hline $\begin{array}{l}\text { Adoption of } \\
\text { New } \\
\text { Technology }\end{array}$ & $0.959^{*}$ & 7.892 & 0.000 \\
\hline $\begin{array}{l}\text { Adoption of } \\
\text { New Process }\end{array}$ & $0.874^{*}$ & 5.098 & 0.000 \\
\hline $\begin{array}{l}\text { F-Statistics = 38.981 (0.0000) } \\
\text { N.B:*: Significant at 5 percent } \\
\text { level }\end{array}$ & $\begin{array}{l}\text { R-Square }=0.838 \\
\text { Adj R-Square }=0.786\end{array}$ \\
\hline
\end{tabular}

Source: Authors' computation from Field Survey (2019) and STATA 14.

Concerning the summary of results on Table 1, it was revealed that business process reengineering components (adoption of new technology and new process) have a positive significant combined effect on the performance of insurance firms' in Nigeria (Fstatistics $=38.981<0.05)$. The adjusted coefficient of determination (adjusted $\mathrm{R}^{2}$ ) suggested that, 78.6\% variation in insurance firms' performance is accounted for by the combined business process reengineering components. The t-statistics revealed that, both adoption of new technology and new process have a positive significant individual effect on insurance firms' performance in Nigeria.

The findings from the study revealed that, the two components of business process reengineering adopted for this study have an individual positive significant effect on insurance firms' performance with coefficients and probability values of: Adoption of new technology $(0.959$, P-Value $<0.05)$ and adoption of new process $(0.874, \mathrm{P}-$ Value $<0.05)$. This is consistent with the study by Okafor and Okeke-Ezeanyanwu (2018), which found that the adoptions of new technology and new processes have positive significant effect on the performance of rice producing firms in South-East, Nigeria. The F-statistics revealed that, the two components of business process reengineering (Adoption of new technology and new process) adopted for this study have a positive significant combined effect on insurance firms' performance in Nigeria (F-statistics= $38.981<0.05)$. The coefficient of determination $\left(\mathrm{R}^{2}\right)$ provided a value of 0.838 . But since there are more than one independent variable (multiple regression), it will therefore be appropriate to use the adjusted coefficient of determination (adjusted $R^{2}$ ) value, which is: Adj $R$ Square $=0.786$. This implies that, $78.6 \%$ change in insurance firms' performance is explained by the combined business process reengineering components (Adoption of new technology and new process). 


\section{Conclusion and Recommendation}

The study investigated the effect of business process reengineering on the performance of insurance firms in Nigeria, by employing two components of business process reengineering (Adoption of new technology and new process). Survey research design was adopted, through the administration of structured questionnaires on some selected staff of insurance companies at their head office in Lagos, Nigeria. The findings revealed that, adoption of new technology and new process has a positive significant individual effect on insurance firms' performance. Furthermore, it was also discovered that, business process reengineering components (adoption of new technology and new process) have a positive significant combined effect on insurance firms' performance in Nigeria.

It is therefore concluded that, business process reengineering components (adoption of new technology and new process) are important drivers of insurance firms' performance. It is recommended that, insurance firms should introduce new technology that will aid insurance penetration, especially information communication technology (ICT). The deployment of ICT tends to make it easier for existing and new customers to pick-up insurance policies through their smart phones or personal computers. Furthermore, insurance firms should equally come up with reengineered processes. Also, the process of serving their customers should be enhanced. As an example, some insurance companies have partnered with some banks, whereby, banks branches are used as centers where insurance policies can be picked-up, and this should be encouraged. The development of online application (Android, Iphone and Windows Apps) for insurance companies should be encouraged.

\section{References}

Hammer, M. (1990). Reengineering work: Don't automatic obliterate. Harvard Business Review.

Hammer M., \& Champy, J. (1993). Reengineering the Corporation: A Manifesto for Business Revolution. Harper Business.

Hammer, M., \& Stanton, S. (2013). How process enterprises really works. Harvard Business Review, 77 (6), 108-118.

Islam, M., \& Mohamed, B. (2011). Impact of organizational innovation on firm performance: evidence from Malaysian-based ICT companies. Retrieved from http:// www.researchgate.net.

Jacob, R. (2014). The relationship between enterprises architecture, business complexity and business performance. Twente. Deloitte.
Kabiru, A., Mohamed, A., \& Norlena, A. (2012). Effect of critical success factors for business process management on the organizational performance of small and medium banks in Nigeria. https://pdfs.semanticscholar.org.

Kemal, A. Yasin, O., \& Zafer, A. (2011). Productivity and performance effects of business process reengineering: a firm level analysis. Journal of Management Information Systems, 27, (4).

Klun, M., \& Trkman, P. (2018). Business process management at the crossroads. Business Process Management Journal, 24(3), 786813, https://doi.org/10.1108/BPMJ-11-20160226.

Kothari, C.R., \& Garg, G. (2014). Research Methodology, Third Edition. New Age International Publishers, New Delhi.

Mura, A., Nilgun, A., \& Fulya, S. (2013). The Relationship between innovation and firm Performance: empirical evidence from Turkish automotive supplier industry. Procedia-Social and Behavioural Sciences, 75, 226-235.

Okafor, P.A., \& Okeke-Ezeanyanwu, J.A. (2018). Business process reengineering and organizational performance of rice production firms: Evidence from South-East, Nigeria. Journal of Arts, Management and Social Science, 3(1), 180-188.

Porter, M. (1984). Competitive advantage. Free Press.

Sharma M. (2006). Business Process Reengineering: A Tool to further Bank Strategic Goals. Journal of Management Information Systems 12: 1.

Simon, K.A. (1994). Towards a theoretical framework for business process reengineering. Retrieved from www.citeseerx.ist.psu.edu/viewdoc/ download?doi:10.1.1.115.6439\&rep.

Tor, G., \& Wendi. (1996). Empirically assessing the impact of business process reengineering on manufacturing firms. Cooke ville, Tennessee. Gestao \& Producao. 